\title{
Immune response to bacteria in seminiferous epithelium
}

\author{
Kaz Nagaosa ${ }^{1,2}$, Chie Nakashima ${ }^{2}$, Atsushi Kishimoto ${ }^{1}$ and Yoshinobu Nakanishi ${ }^{1,2,3}$ \\ ${ }^{1}$ Graduate School of Natural Science and Technology, ${ }^{2}$ Faculty of Pharmaceutical Sciences and ${ }^{3}$ Graduate School of \\ Medical Science, Kanazawa University, Kanazawa, Ishikawa 920-1192, Japan
}

Correspondence should be addressed to Y Nakanishi; Email: nakanaka@kenroku.kanazawa-u.ac.jp

\begin{abstract}
The luminal part of the seminiferous epithelium, a tissue compartment protected by the blood-testis barrier, has been considered a site of immune privilege. However, there are reports describing the production of anti-microbial peptides and the expression of Toll-like receptors in cells present in the seminiferous epithelium, evoking the possibility that this tissue compartment is immunologically active at least with regard to the innate immune response. To test this, we injected Escherichia coli into seminiferous tubules of live mice and examined the fate of bacteria, the production of chemokines and inflammatory cytokines, and the infiltration of neutrophils. The bacteria actively propagated and reached a maximal level in a day, but started to decrease after $\mathbf{5}$ days and completely disappeared in $\mathbf{2}$ months. The expression of macrophage inflammatory protein- 2 and tumor necrosis factor- $\alpha$ became evident in macrophages present in the interstitial compartment of testes as early as 1-3 $\mathrm{h}$ after the inoculation of bacteria. Neutrophils first accumulated in the interstitial space at 9-12 $\mathrm{h}$ and entered the tubules after a day. On the other hand, impairment of spermatogenesis was observed a day after bacteria injection and seemed unrecoverable even after the bacteria were eliminated. By contrast, bacteria injected into the interstitial compartment were more rapidly cleared with no damage in the seminiferous epithelium. These results suggest the existence of immunity against invading microbes in the seminiferous epithelium although its effectiveness in maintaining tissue homeostasis remains equivocal. Reproduction (2009) 137 879-888
\end{abstract}

\section{Introduction}

Mammalian spermatogenesis takes place in the luminal portion of seminiferous tubules, a tissue compartment protected by a permeability barrier across the epithelium and endothelium of the tubules. This barrier that is called the blood-testis barrier or the seminiferous epithelium barrier is composed of inter-Sertoli tight junctions and protects the seminiferous epithelium from invasion by molecules or cells that may perturb the process of spermatogenesis (Lui et al. 2003). The blood-testis barrier, at the same time, needs to be temporarily lost at particular stages of spermatogenesis for the movement of germ cells across the inter-Sertoli junction (Lui et al. 2003, Lui \& Lee 2006, Wang \& Cheng 2007). In addition, there are cytokines and chemicals that disrupt this barrier and increase permeability (Hew et al. 1993, Wiebe et al. 2000, Xia et al. 2005). Furthermore, tight junctions become structurally and functionally deficient upon infection with some microbes (Guttman et al. 2006). On the other hand, microbes may infect testes in a retrograde manner through the male excurrent ducts (Bhushan et al. 2008a). These facts indicate that the seminiferous epithelium could be exposed to hazardous substances including microbial pathogens. In fact, previous studies showed that the introduction of bacteria into the epididymis (Demir et al. 2007) or the testis (Mukasa et al. 1995) causes orchitis.

Immunologically privileged sites that are exemplified by the brain (Carson et al. 2006), the eye (Niederkorn 2007), the testis (Fijak \& Meinhardt 2006), and the uterus (Hunt 2006) are organs or tissues where allografts are hardly rejected. Immunotolerance in the testis may be attributed to both physical and immunological factors; the blood-testis barrier limits the movement of immune cells, and the level of cytokines in the seminiferous epithelium is balanced toward a tolerogenic environment (Fijak \& Meinhardt 2006). In addition, Fas ligand-expressing Sertoli cells may induce apoptosis in Fas-expressing immune cells such as lymphocytes (Bellgrau et al. 1995, Griffith et al. 1995). On the other hand, there are indications of innate immune responses in the seminiferous epithelium. Sertoli cells, the only somatic cell type constituting the seminiferous epithelium, possess characteristics of immune cells: they phagocytose apoptotic spermatogenic cells (Nakanishi \& Shiratsuchi 2004); express pattern recognition receptors such as Toll-like receptors (Riccioli et al. 2006, Girling \& Hedger 2007, Palladino et al. 2007, Wu et al. 2008); and produce anti-microbial proteins (Grandjean et al. 1997, Lennartsson et al. 2005, Sang et al. 2005). Furthermore, the expression of Toll-like receptors in 
germ cells was recently reported (Bhushan et al. 2008b). To directly examine the occurrence of immune responses in the seminiferous epithelium, we injected bacteria into the seminiferous tubules of live mice, and determined the fate of bacteria, the production of chemokines and inflammatory cytokines, and the infiltration of neutrophils.

\section{Results}

\section{Propagation and eventual disappearance of Escherichia coli in seminiferous tubules}

We first examined, if bacteria grow in the seminiferous epithelia. E. coli were injected into seminiferous tubules or the interstitial compartment of testes in live mice, and the level of viable bacteria in testes was determined in the following days (Fig. 1A). The injected bacteria appeared to have actively propagated in seminiferous tubules and reached a maximal level within a day, and this level was maintained for the next 2 days. By contrast, bacteria injected into the interstitial space of testes did not seem to grow and had almost disappeared after 4 days (Fig. $1 \mathrm{~A}$ ), indicating that immune cells existing in the interstitium eliminated the bacteria. To know if bacteria are removed when the initial number is smaller, varying numbers of $E$. coli were injected into seminiferous tubules, and the level of bacteria was determined after 3 days (Fig. 1B). We found that even a small number of bacteria, as few as 10 cells per testis, grew in the testis, and the level of colony-forming bacteria on day 3 was almost the same between injections with 100 and a million bacteria, suggesting that immunity in the seminiferous epithelium, if it exists at all, is ineffective against invading bacteria unlike that in the interstitial space. The bacteria in seminiferous tubules gradually decreased afterward and had almost completely disappeared on day 56 (Fig. 1C). It was, however, uncertain if the disappearance of once-growing bacteria at later stages was due to immune responses in the seminiferous epithelium.

\section{Expression of macrophage inflammatory protein (Cxcl2) mRNA in macrophages present in interstitium}

To examine the occurrence of immune responses, we analyzed the expression of chemokines and inflammatory cytokines in testes before and after the injection of E. coli. RNA was prepared from the whole testes and subjected to semi-quantitative RT-PCR, and the levels of all mRNA tested were found to increase as early as $1 \mathrm{~h}$ after the injection of bacteria into seminiferous tubules (Fig. 2A). However, the amount of mRNA of some proteins also increased when PBS alone was injected, and only the production of mRNA of Cxcl2 and tumor necrosis factor $\alpha(T n f)$ responded to the injection of bacteria (Fig. 2B).
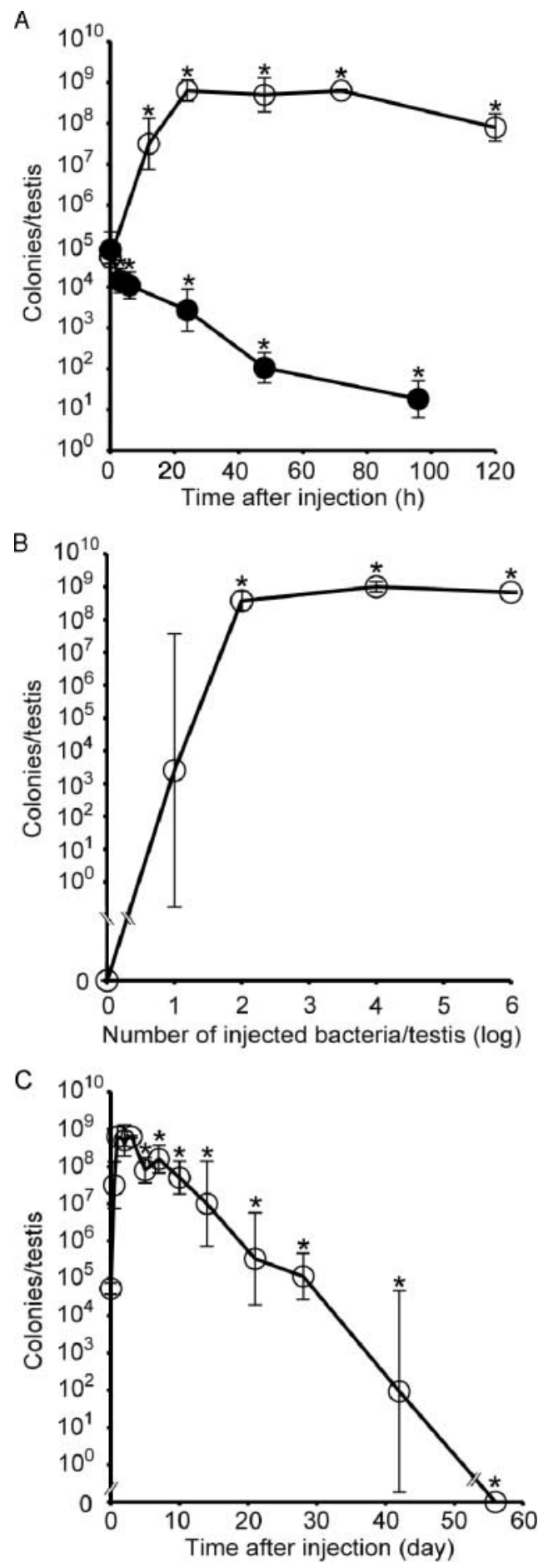

Figure 1 Growth of E. coli injected into testes. One million (A and C) or the indicated number $(B)$ of $E$. coli were injected into seminiferous tubules (open circles) or the interstitial space (closed circles) of testes in live mice. Homogenates were prepared from testes at the indicated time points (on day 3 in B), and the level of colony-forming bacteria was determined. The data are the mean \pm s.D. $(n=3$ except for the data at $24 \mathrm{~h}$ (open circle) in A and on day 1 in C with $n=5$ ). 
A
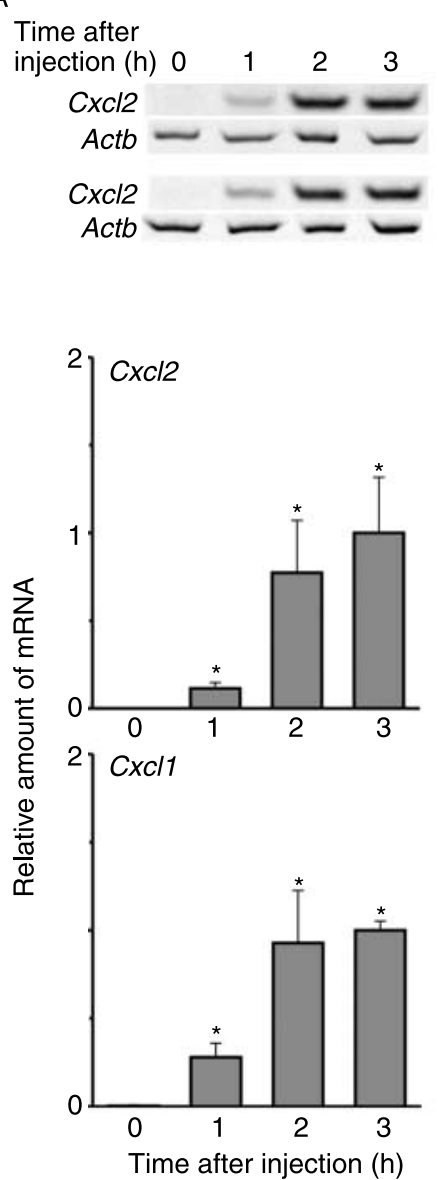

B
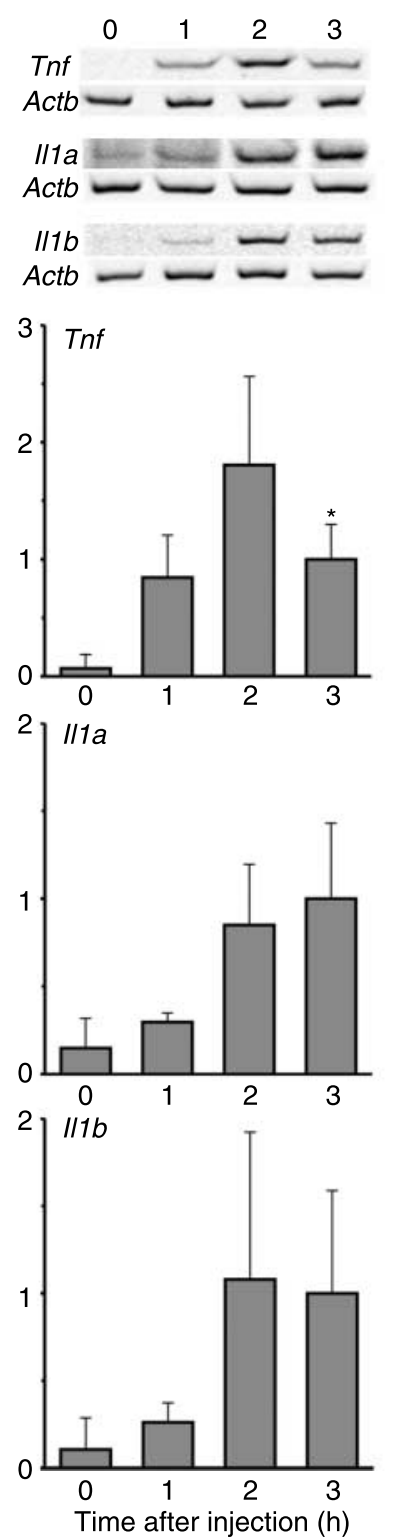
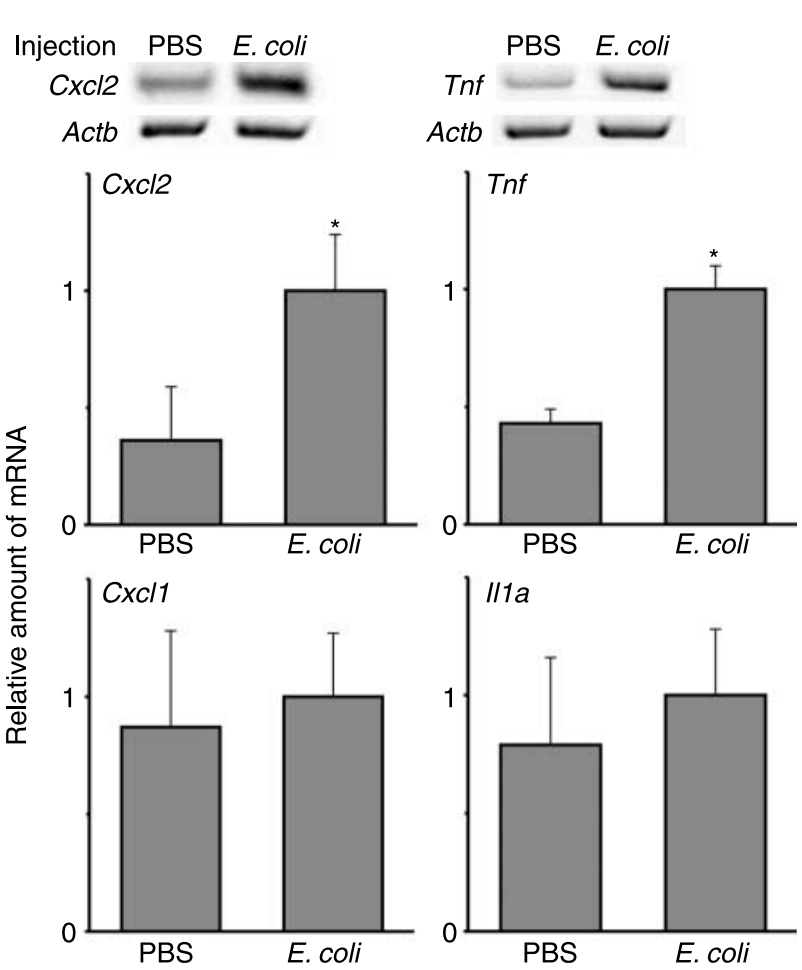

Figure 2 Increase in mRNA of chemokines and cytokines in testes after injection with $E$. coli. One million $E$. coli or PBS alone was injected into seminiferous tubules of live mice. RNA was prepared from the testes at the indicated time points (at $3 \mathrm{~h}$ in B) and subjected to semi-quantitative RT-PCR for the detection of mRNA of the indicated chemokines and cytokines as well as that of $\beta$-actin (Actb) as a loading control. The intensity of PCR signals was digitized and shown relative to that at $3 \mathrm{~h}$ in $\mathrm{A}$ and that with RNA from testes injected with $E$. coli in $\mathrm{B}$. The data from numerical analyses are expressed as the mean \pm s.D. $(n=3)$.

We then determined the cell types that express $\mathrm{CxCl} 2$ and Tnf in response to the invasion of bacteria. Testes were injected with $E$. coli at seminiferous tubules, sectioned after $3 \mathrm{~h}$, and subjected to in situ hybridization. The signals from either mRNA were detected only in the interstitial space (Fig. $3 \mathrm{~A}$ and $\mathrm{B}$ ). The sections were then simultaneously analyzed by in situ hybridization and immunohistochemistry with antibody recognizing F4/80, a marker protein of macrophages, because the cells expressing the mRNA were unlikely Leydig cells.
We found that cells containing the signals derived from mRNA of both $\mathrm{CxCl} 2$ and Tnf were also positive for the macrophage marker (Fig. 3C). These results indicated that macrophages existing in the interstitium express $\mathrm{CxCl} 2$ and Tnf in response to the injected E. coli. De et al. (1993) showed the existence of Tnf mRNA in both macrophages and spermatogenic cells of uninfected adult mice. The discrepancy between the two results could be due to a difference in the mouse strains or experimental procedures adopted in the studies. 
A
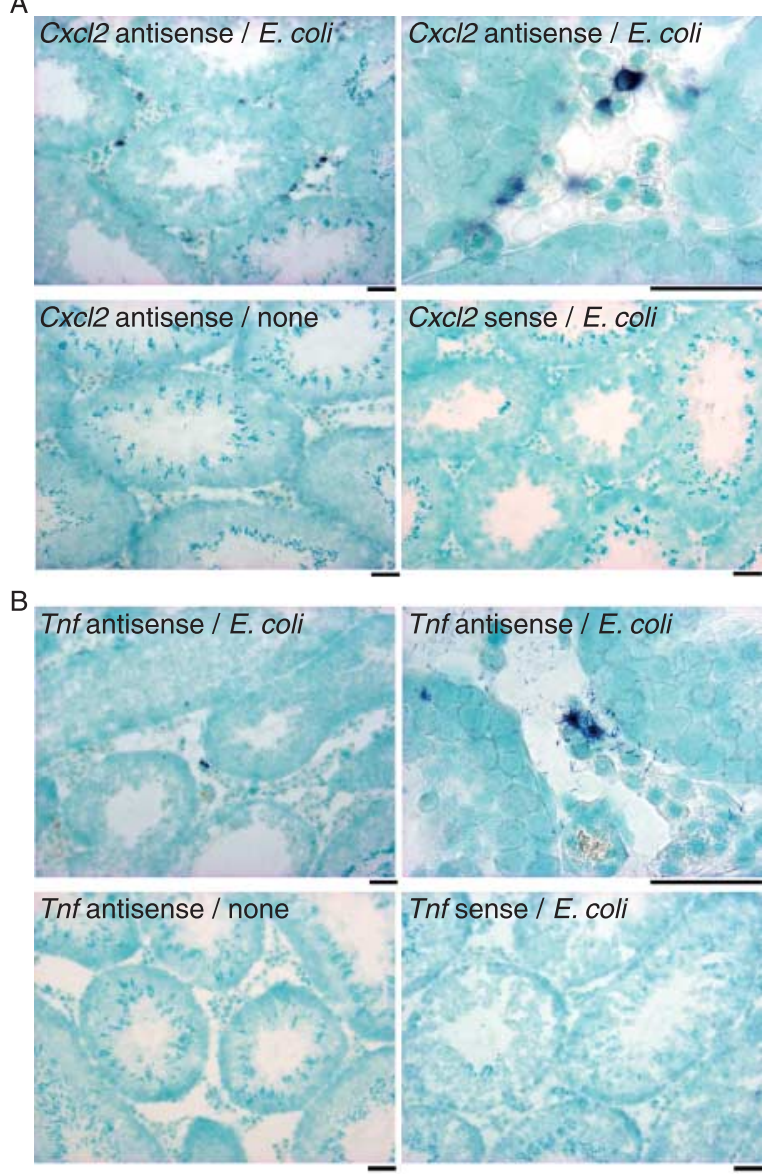

\section{$\mathrm{C}$}
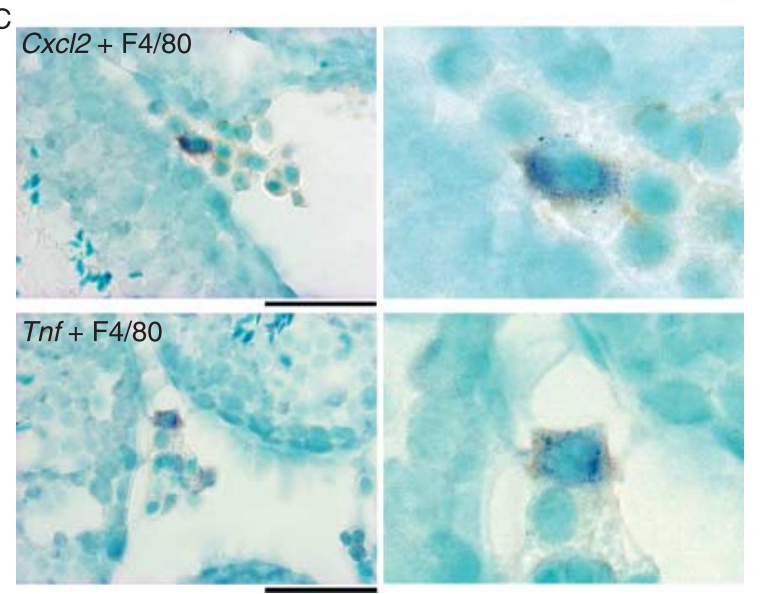

Figure 3 Presence of mRNA of $\mathrm{CxCl} 2$ and Tnf in macrophages in E. coliinjected testes. One million (A and B) or trillion (C) E. coli were injected into seminiferous tubules of live mice. The testes after $3 \mathrm{~h}$ together with testes with no injection (none) were subjected to in situ hybridization with antisense or sense probes containing the sequences of mRNA of Cxcl2 (A) and $\operatorname{Tnf}(\mathrm{B})$. The hybridization signals are seen in dark blue, and counter-stained nuclei are stained light blue. In $\mathrm{C}$, the sections were simultaneously analyzed for the macrophage marker protein $\mathrm{F} 4 / 80$ (seen in brown), and panels on the right are magnified views of F4/80-positive cells in the corresponding left panels. Three to five testes were used in each experiment, and data are representative of at least three independent experiments that yielded similar results. Scale bars represent $100 \mu \mathrm{m}$.

\section{Accumulation of neutrophils in testes after the injection of $\mathrm{E}$. coli}

The expression of the chemokine $\mathrm{CxCl} 2$ upon the injection of bacteria suggested the accumulation of immune cells in the seminiferous epithelium. To examine this, we immunochemically analyzed sections of testes for the presence of neutrophils. The accumulation of neutrophils in the interstitium was evident 9-12 h after the injection of E. coli into seminiferous tubules (Fig. 4A and B). This was not observed in the uninjected collateral testes (Fig. 4B) or in the testes that received the injection with PBS alone (Fig. 4C). These results indicated that neutrophils migrated toward the site of $\mathrm{CxCl} 2$ expression. Neutrophil accumulation occurred earlier when bacteria were inoculated into the interstitial space (Fig. 4B). Furthermore, neutrophils became detectable within seminiferous tubules after a day or two (Fig. 4A and D), and this did not occur in the testes where bacteria were injected into the interstitial space (Fig. 4D). The inoculation of dead E. coli or lipopolysaccharide (LPS) into seminiferous tubules caused neutrophil accumulation in the interstitial space (data not shown), but those neutrophils never entered the tubules (Fig. 4E). We found that E. coli and neutrophils partly coexisted within seminiferous tubules (Fig. 4F), suggesting the occurrence of phagocytosis of the injected bacteria by infiltrating neutrophils.

\section{Impairment of seminiferous epithelium after bacterial injection}

We next determined cytological changes of the seminiferous epithelium after the inoculation of bacteria. A day after the injection, the concentric lining of spermatogenic cells was found to be irregular with a decrease in cell number when cross-sections of seminiferous tubules were examined (Fig. 5A), and most seminiferous tubules seemed to have been morphologically impaired within 2 days (Fig. 5B). Disruption of the inter-Sertoli tight junction seemed likely at later stages (Fig. 5A), which probably allowed neutrophils that had accumulated in the interstitial space to enter seminiferous tubules (Fig. 4A and D). By contrast, impairment of the seminiferous epithelium was not evident in testes where bacteria were injected into the interstitium (Fig. 5B) or in the uninjected collateral testes of mice that had received the injection at seminiferous tubules (Fig. 5B and C). In addition, the injection of either dead bacteria or LPS into seminiferous tubules did not severely damage the seminiferous epithelium (Fig. 5C). These results indicated that bacteria not only propagated in seminiferous tubules but also damaged the seminiferous epithelium. The testes increased in weight soon after the injection, but their weight gradually decreased thereafter and was less than that of the control after 40 days (Fig. 5D). The seminiferous epithelium did not seem to have recovered from the damage even after bacteria were eliminated (Fig. 5E). 
A Day
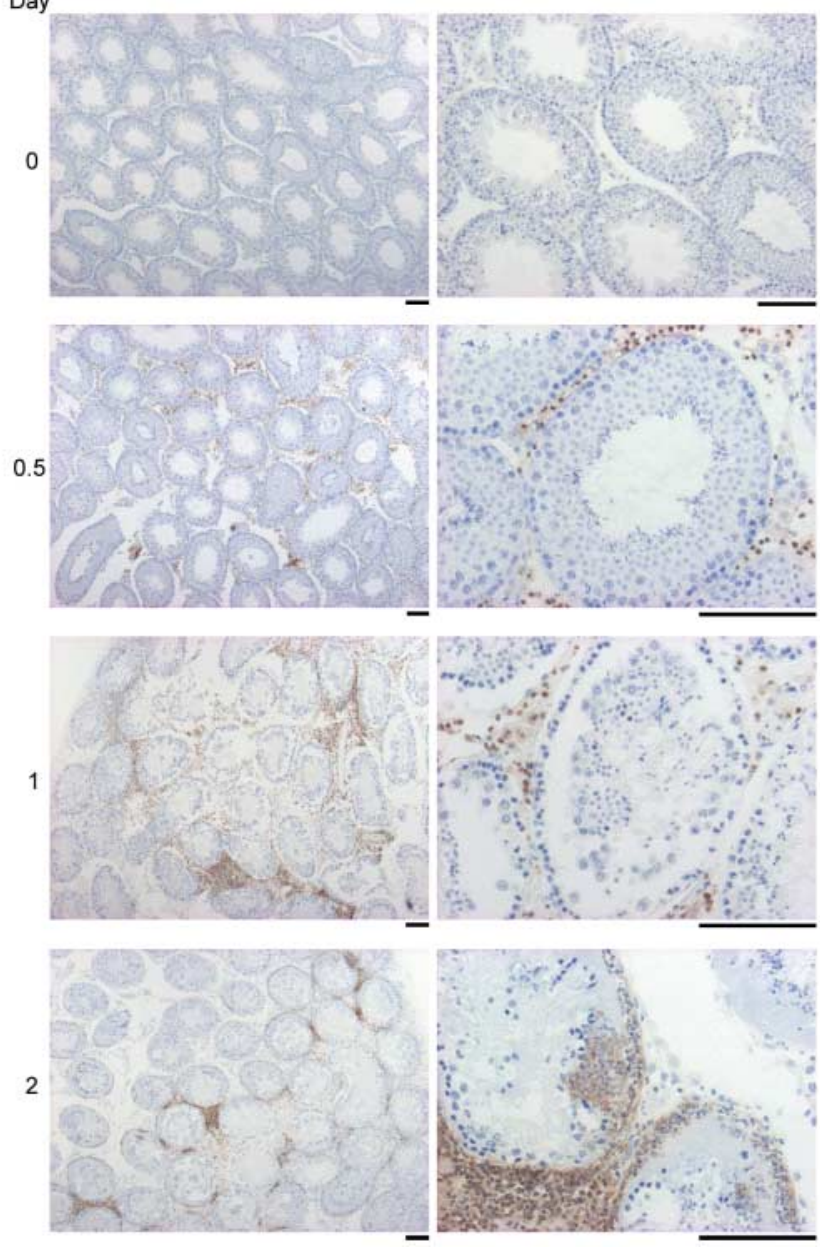
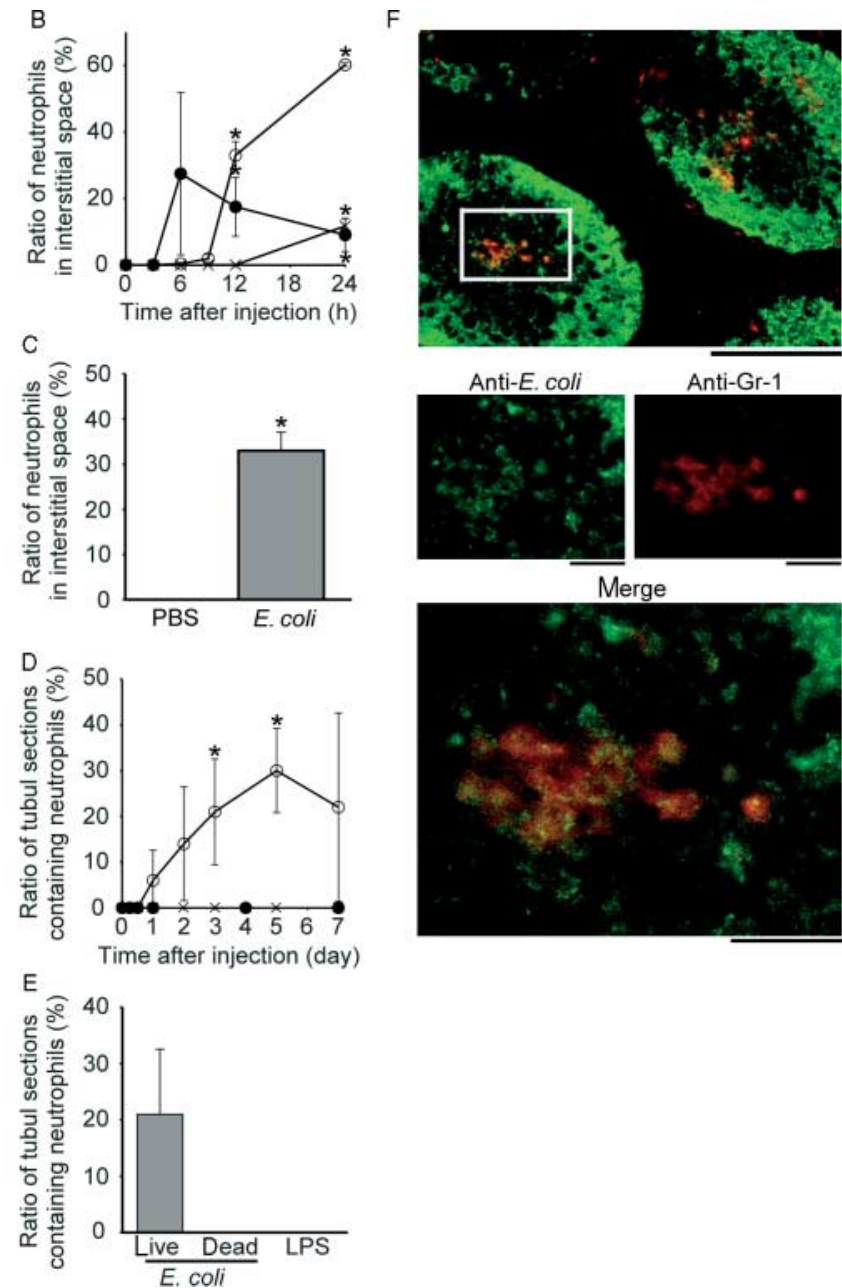

Figure 4 Accumulation of neutrophils in E. coli-injected testes. One million E. coli were injected into seminiferous tubules $(\mathrm{A}, \mathrm{C}, \mathrm{E}$, and $\mathrm{F}$, and open circles in B and D) or the interstitial compartment (closed circles in B and D) of testes in live mice. PBS alone (C), paraformaldehyde-treated dead E. coli (one million) (E), or LPS (20 $\mu \mathrm{g}$ ) (E) was similarly injected into seminiferous tubules. The data with the symbol ' $X$ ' in B and D are results from the analysis of the uninjected collateral testes of mice that had received bacteria injection at seminiferous tubules. The testes were immunohistochemically analyzed for the presence of Gr-1 (stained brown in A and red in F), a marker protein for neutrophils, at the indicated time points (at $12 \mathrm{~h}$ in $\mathrm{C}$, on day 3 in $\mathrm{E}$, and on day 2 in F). In F, E. coli (seen in green), and neutrophils were simultaneously detected, and micrographs in the middle and bottom rows are magnified views of the squared area in the top micrograph. The data from numerical analyses are expressed as the mean \pm s.D. $(n=3)$. Scale bars represent $100 \mu \mathrm{m}(\mathrm{A})$ and $20 \mu \mathrm{m}(\mathrm{F})$.

\section{Discussion}

Compared with urethritis or epididymo-orchitis, the development of orchitis is rare. This is presumably due to immunity that combats against invading bacteria in the seminiferous epithelium. Results from the present study showed that immune reactions are evoked in response to bacteria inoculated into the seminiferous epithelium, evidenced by the production of chemokines and inflammatory cytokines, and the subsequent infiltration of neutrophils into the interstitial compartment of testes. However, such responses seemed not to be enough to eliminate the bacteria before they damage spermatogenesis, probably due to inter-Sertoli tight junctions that prevent immune cells from entering the tubules. Bacteria that had grown in the seminiferous epithelium were eventually removed after the morphology of the tubules was destroyed, which probably allowed immune cells, such as neutrophils, to come close and phagocytose the bacteria. As a result, the development of a systemic infection was prevented although the machinery for sperm production was impaired. By contrast, bacteria injected into the interstitial space were rapidly removed without damage in the seminiferous epithelium. This indicates the level of immune response to be higher in the interstitial compartment of testes than in the seminiferous epithelium. The bottom line is that immunity in the seminiferous epithelium is not effective enough to preclude damage in the testis caused by invading bacteria. 

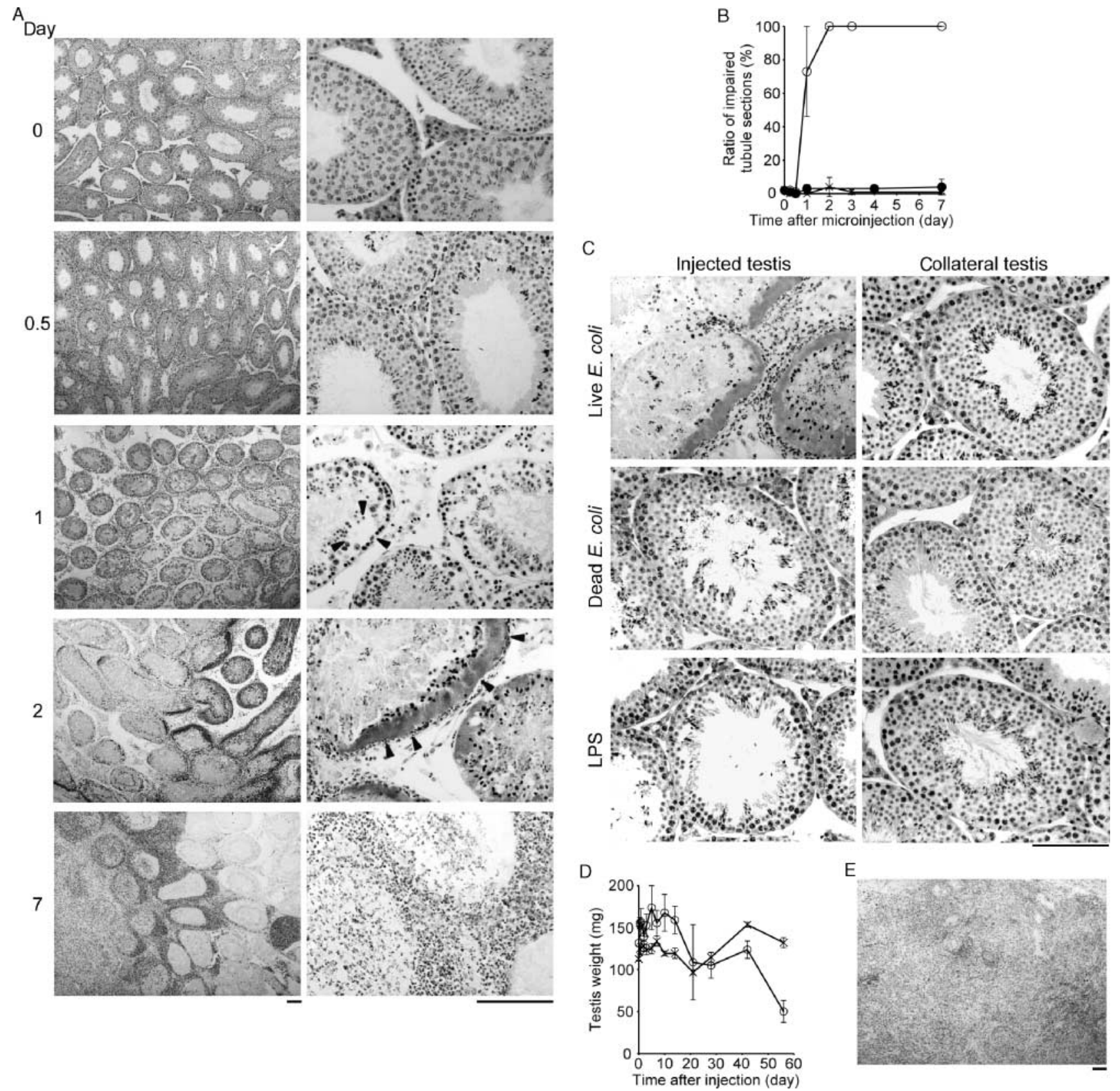

Figure 5 Histological changes of testes after injection with E. coli. One million E. coli were injected into seminiferous tubules (A, C and E, and open circles in B and D) or the interstitial compartment (closed circles in B) of testes in live mice. In C, dead E. coli (one million) or LPS (20 $\mu$ g) was injected into seminiferous tubules. The testes were analyzed for changes in morphology (A, B, C, and E) and weight (D) at the indicated time points (on day 3 in $C$ and day 56 in $E$ ). In $A$, the arrowheads denote the appearance of vacuoles (day 1 ) and the accumulation of $E$. coli (day 2). The data with the symbol ' $X$ ' in $B$ and $D$ are results from the analysis of the uninjected collateral testes of mice that had received bacteria injection at seminiferous tubules. The data from numerical analyses are expressed as the mean \pm s.D. ( $n=3$ in B and $n=3-9$ in D). Scale bars represent $100 \mu \mathrm{m}$.

The mRNAs of the chemokine Cxcl2 and the inflammatory cytokine Tnf were produced in macrophages present in the interstitial space in response to the injection of bacteria into the seminiferous epithelium. It is not known at the present time how the expression of these mRNAs is induced in macrophages present apart from the injected bacteria. We speculate that cells within the seminiferous epithelium secrete, in response to bacteria, factors that trigger macrophages to express $\mathrm{CxCl} 2$ and Tnf. Another possibility is that bacteria escape from the seminiferous epithelium and are recognized by macrophages in the interstitial space. Inter-Sertoli tight junctions open temporarily during the spermatogenic cycle (Lui et al. 2003, Lui \& Lee 2006, Wang \& Cheng 2007), and therefore bacteria may leave even before the seminiferous tubules are damaged. The latter possibility 
is, however, less likely because macrophages expressing the mRNA of the chemokine and cytokine were not always localized near the seminiferous tubules at certain spermatogenic stages (stage VIII for the mouse) when the inter-Sertoli tight junction is physiologically lost (data not shown). In response to the inoculated bacteria, neutrophils first accumulated in the interstitial space and then entered the seminiferous epithelium after interSertoli tight junctions were lost. CXCL2 is most probably responsible for the infiltration of neutrophils because the injection of PBS alone, which induced mRNA expression of another chemokine KC (CxCl1: chemokine (c-X-C motif) ligand 1), was not followed by the accumulation of neutrophils. Although TNF is presumed to act as a pro-inflammatory cytokine, we anticipate another role for this cytokine. The most prominent damage in testes was the appearance of vacuoles in seminiferous tubules. This could be caused by TNF, which has been known to weaken ectoplasmic specialization (Siu et al. 2003, Lui \& Cheng 2007). Neutrophils that had accumulated in the interstitial space did not instantly enter morphologically impaired seminiferous tubules. This suggests the existence of another mechanism for the regulation of the movement of immune cells in the testis, in addition to a physical barrier of the inter-Sertoli tight junctions. Neutrophils that express Fas (Iwai et al. 1994) may be induced to undergo apoptosis when they touch Fas ligand-expressing Sertoli cells (Bellgrau et al. 1995, Griffith et al. 1995).

It is uncertain at present how E. coli impairs the seminiferous epithelium. Previous studies described negative effects of $E$. coli on the function and viability of isolated testicular cells including germ cells, Sertoli cells, and peritubular cells (Sanocka-Maciejewska et al. 2005, Fraczek et al. 2007, Bhushan et al. 2008b). The growth of $E$. coli within seminiferous tubules seemed to be required for their inhibitory actions because the inoculation of dead E. coli did not have a devastating effect on the seminiferous epithelium. In some infectious diseases, excessive immune responses of host organisms may explain or enhance the pathogenicity. In fact, the injection of LPS, a ligand for Toll-like receptor 4 to induce an inflammatory response, into the peritoneal cavity of the mouse results in a temporal inhibition of sperm production (Gow et al. 2001, Gerdprasert et al. 2002). However, in our study LPS only marginally affected spermatogenesis when injected into the seminiferous tubules. This suggests that LPS-caused inflammatory process plays little role in the $E$. coli-induced impairment of the seminiferous epithelium.

In summary, the present study suggests the presence of immunity in the seminiferous epithelium. However, its effectiveness is questionable in terms of the prevention of defects in sperm production, and cell types that participate in this immunity remain to be determined. Further work is necessary to solve these issues.

\section{Materials and Methods}

\section{Animals and injection of bacteria}

All experiments involving animals were conducted according to protocols that had been approved by the Animal Ethics Committees of Kanazawa University. Male ddY mice (10-20week-old, weighing 36-51 g; Nihon SLC, Shizuoka, Japan) were used throughout the study. They were housed at $22-25{ }^{\circ} \mathrm{C}$ under $12 \mathrm{~h}$ light:12 $\mathrm{h}$ darkness cycle with free access to water and food. E. coli strain W3110 (provided by Dr Kazuhisa Sekimizu, Graduate School of Pharmaceutical Sciences, the University of Tokyo), a derivative of the non-pathogenic intestinal $E$. coli strain K-12 isolated from human feces, was used throughout this study. Although E. coli is a main pathogen of infection-based infertility, this particular strain has thus far not been found to be associated with male infertility. The bacteria grown with Luria broth were harvested at the logarithmic phase by centrifugation, washed twice with PBS, and suspended with PBS. E. coli that had been incubated with $4 \%$ (w/v) paraformaldehyde at $4{ }^{\circ} \mathrm{C}$ for $10 \mathrm{~h}$ with gentle agitation was used as dead bacteria. The bacteria-suspension (about $20 \mu \mathrm{l}$ ), which was supplemented with $0.05 \%(\mathrm{w} / \mathrm{v})$ Trypan blue to monitor the distribution of the injected materials in seminiferous tubules, was injected into seminiferous tubules from the efferent duct using a glass needle as described previously (Maeda et al. 2002, Nakagawa et al. 2005, Nagaosa et al. 2007). LPS obtained from E. coli O111:B4 (catalogue \# L-2630, Sigma-Aldrich) was similarly injected into seminiferous tubules. An injection was considered to be successful when $>40 \%$ of the testis was stained blue shortly after the injection without leakage of the fluid into the interstitial space. The same materials were also introduced into the interstitial space of testes from tunica vaginalis using a 27-gauge needle. The mice were maintained as described above until examination of the testes.

\section{Histochemistry}

Mice were killed by cervical dislocation, and the testes were collected. For in situ hybridization, testes were successively incubated with $4 \%$ paraformaldehyde in PBS, 10\% (w/v) sucrose in PBS, and 20\% sucrose in PBS for fixation before being embedded in OCT compound (Sakura Finetechnical Co. Ltd, Tokyo, Japan). For the other experiments, testes were immersed in Bouin's solution, 70\% (v/v) ethanol, 100\% ethanol, and xylene for fixation before being embedded in paraffin. Sections $(10 \mu \mathrm{m}$ thick for in situ hybridization and $5 \mu \mathrm{m}$ thick for the other experiments) were prepared and processed as described below. To examine morphological changes of testes, the sections were stained with Mayer's hematoxylin (Wako Pure Chemical Industries Ltd, Osaka, Japan) and eosin (Merck KGaA) for visualizing nuclei and the cytosolic area, dehydrated, covered with Entellan New (Merck $\mathrm{KGaA}$ ), and examined by microscopy. The histology of crosssections of seminiferous tubules was examined, and those with vacuoles of $>100 \mu \mathrm{m}^{2}$ besides the lumen, occupied by injected bacteria, or with spermatogenic cells distributed non-concentrically were counted as being deteriorated or damaged. For the immunohistochemical detection of Gr-1, a 
marker for neutrophils, the sections were incubated with PBS containing $0.3 \%(\mathrm{v} / \mathrm{v})$ Triton $\mathrm{X}-100$ for membrane permeabilization, immersed in methanol containing $0.3 \%(\mathrm{w} / \mathrm{v}) \mathrm{H}_{2} \mathrm{O}_{2}$ to inactivate endogenous peroxidase, and treated with $10 \%$ $(\mathrm{v} / \mathrm{v})$ fetal bovine serum for blocking. The samples were reacted first with anti-mouse Gr-1 rat MAB (BD Biosciences, San Jose, CA, USA), then with biotin-conjugated anti-rat immunoglobulin $\mathrm{G}$ goat polyclonal antibody (Vector Laboratories, Burlingame, CA, USA), and incubated with peroxidaseconjugated streptavidin (Amersham Biosciences). They were subjected to a coloring reaction containing 3, 3'-diaminobenzidine tetrahydrochloride, counterstained with Mayer's hematoxylin, dehydrated, covered with Entellan New, and finally examined by microscopy. For the simultaneous detection of Gr-1 and E. coli proteins, the sections that had been treated with anti-Gr-1 antibody and a biotin-conjugated secondary antibody were further incubated with anti-E. coli rabbit polyclonal antibody (Virostat, Portland, ME, USA), then with Alexafluoro 546-conjugated streptavidin (Invitrogen Corporation) and FITC-conjugated anti-rabbit immunoglobulin $\mathrm{G}$ goat polyclonal antibody (Vector Laboratories). The samples were covered with $10 \mathrm{mM}$ Tris- $\mathrm{HCl}(\mathrm{pH} 8.8)$ containing $50 \% \quad(\mathrm{v} / \mathrm{v})$ glycerol and $0.5 \% \quad(\mathrm{v} / \mathrm{v})$ 2-mercaptoethanol and examined by microscopy. In situ detection of mRNA of $\mathrm{CxCl} 2$ and Tnf in the sections was carried out using RNA probes, as previously described (Nagaosa et al. 2002). DNA corresponding to a part of the mRNA of mouse $C x c / 2$ or mouse Tnf (cDNA of mouse Tnf was provided by Dr Naofumi Mukaida of Cancer Research Institute, Kanazawa University) was inserted into the vector pBluescript II SK + (Stratagene, La Jolla, CA, USA) and used as a template for the synthesis of probes. RNA probes with both antisense and sense sequences were synthesized in vitro in the presence of digoxigenin-labeled UTP (Dig RNA Labeling Kit; Roche Diagnostics) and dissolved in hybridization buffer consisting of $20 \mathrm{mM}$ Tris- $\mathrm{HCl}(\mathrm{pH} 8), 2.5 \mathrm{mM}$ EDTA, $0.3 \mathrm{M}$ $\mathrm{NaCl}, 10 \%(\mathrm{w} / \mathrm{v})$ dexstran sulfate, $1 \times$ Denhardt solution, $1 \mathrm{mg} / \mathrm{ml}$ of yeast RNA, and $50 \%(\mathrm{v} / \mathrm{v})$ formamide. The sections were treated successively with $0.3 \%$ Triton X-100, proteinase $\mathrm{K}(1 \mu \mathrm{g} / \mathrm{ml})$, and $4 \%$ paraformaldehyde. They were then incubated with hybridization buffer containing the RNA probe incubated at $60{ }^{\circ} \mathrm{C}$ (for $\mathrm{CxCl}$ ) or $70{ }^{\circ} \mathrm{C}$ (for Tnf) for $16 \mathrm{~h}$, treated with RNase $\mathrm{A}$ to remove free RNA probe, and supplemented with alkaline phosphatase-conjugated antidigoxigenin sheep polyclonal antibody (Roche Diagnostics). The samples were subjected to a coloring reaction with nitro blue tetrazolium (Roche Diagnostics) and 5-bromo-4-chloro3-indolylphosphate, 4-toluidine salt (Roche Diagnostics) for visualization of the hybridization signals. They were finally counterstained with methyl green, dehydrated, covered with Entellan New, and examined by microscopy. For simultaneously detecting the hybridization signals and F4/80, a marker for macrophages, the sections were treated with Triton X-100 for membrane permeabilization, immersed in PBS containing $3 \% \mathrm{H}_{2} \mathrm{O}_{2}$ to inactivate endogenous peroxidase, and incubated with $5 \%$ swine serum for blocking. They were then reacted with anti-mouse F4/80 rat MAB (AbD Serotec, Raleigh, NC, USA) and subsequently processed as done for the detection of Gr-1. After visualization of the signal derived from F4/80, in situ hybridization was performed as described above.

To determine the degree to which seminiferous tubules were either damaged or infiltrated with neutrophils, 100 crosssections of the tubules randomly chosen from each tissue section of four that had been prepared from one testis and cytohistochemically processed were examined, and positive cross-sections were enumerated. The values obtained with four tissue sections were averaged, and the mean and s.D. were calculated from results obtained with three testes. For determining the extent to which the interstitial space was infiltrated by neutrophils, more than 100 cells present in the interstitial space with one microscopic view were examined for the ratio of neutrophils. The values obtained with three microscopic views for each tissue section out of four that had been prepared from one testis and immunohistochemically processed were averaged, and the mean and S.D. were calculated from results obtained with three testes.

\section{RT-PCR}

Semi-quantitative RT-PCR was conducted essentially as described previously (Chomczynski \& Sacchi 1987, Nagaosa et al. 2003, 2008). In brief, total RNA extracted from 3-5 whole testes was used as a template in RT reactions with ReverTra Ace (Toyobo Co. Ltd, Osaka, Japan) and oligo d(T) as a primer, and the resulting cDNA was then used as a template

Table 1 Conditions for PCR.

\begin{tabular}{|c|c|c|c|c|}
\hline mRNA & Primer sequence $^{a}$ & Product size $(b p)$ & cDNA $(\mu \mathrm{l})^{\mathrm{b}}$ & Reference \\
\hline $\mathrm{CxCl} 2$ & F: AAGTTTGCCTTGACССТGAA & 180 & 1 & Stefanovic et al. (2005) \\
\hline & R: AGGCACATCAGGTACGATCC & & & \\
\hline Cxcl1 & $\begin{array}{l}\text { F: TCGCCAATGAGCTGCGCTGTC } \\
\text { R: GCTTCAGGGTCAAGGCAAGCC }\end{array}$ & 160 & 0.4 & Stefanovic et al. (2005) \\
\hline Tnf & $\begin{array}{l}\text { F: CAGCCTCTTCTCATTCCTGCTTGTG } \\
\text { R: CTGGAAGACTCCTCCCAGGTATAT }\end{array}$ & 511 & 1 & Ishida et al. (2006) \\
\hline $1 / 1 a$ & $\begin{array}{l}\text { F: TGGCCAAAGTTCCTGACTTGTTTG } \\
\text { R: CAGGCTATTTAACCAAGTGGTGCT }\end{array}$ & 488 & 1 & Ishida et al. (2006) \\
\hline $1 / 1 b$ & $\begin{array}{l}\text { F: CAAGGCCACAGGTATTTTGT } \\
\text { R: GAAATGCCACCTTTTGACAG }\end{array}$ & 504 & 0.4 & Ishida et al. (2006) \\
\hline$A c t b$ & $\begin{array}{l}\text { F: TTCTACAATGAGCTGCGTGTGGC } \\
\text { R: CTCATAGCTCTTCTCCAGGGAGGA }\end{array}$ & 456 & 0.02 & Ishida et al. (2006) \\
\hline
\end{tabular}

${ }^{\mathrm{a}} \mathrm{F}$, forward primer; R, reverse primer. ${ }^{\mathrm{b}}$ The amount of cDNA template (in volume) used in PCR is indicated. One $\mu \mathrm{l}$ corresponds to one 600 th of cDNA obtained from a testis. 
in PCR to amplify the sequences of mRNA of Cxcl2, Cxcl1, Tnf, I/1a, I/1b, and Actb using Go Taq DNA polymerase (Promega). We verified the annealing temperature, the number of DNA synthesis cycles, and the amount of cDNA template so that DNA was amplified at the exponential phase. We eventually found that amplification of the DNA sequences corresponding to all the mRNAs analyzed can be done at the exponential phase with the same annealing temperature and amplification cycles by varying the amounts of cDNA in each reaction (Table 1). Reaction mixtures were heated at $95{ }^{\circ} \mathrm{C}$ for $2 \mathrm{~min}$ and subsequently subjected to 25 cycles of amplification with consecutive incubation at $95^{\circ} \mathrm{C}$ for $0.5 \mathrm{~min}$, at $60{ }^{\circ} \mathrm{C}$ for $0.5 \mathrm{~min}$, and at $72{ }^{\circ} \mathrm{C}$ for $1 \mathrm{~min}$. Nucleotide sequences of the primers and other information regarding PCR are described in Table 1. The amplified DNA was separated by $6 \%(\mathrm{w} / \mathrm{v})$ PAGE, stained with ethidium bromide, and visualized using Gel Doc (Bio-Rad Laboratories). The intensity of the signals was determined using Molecular Analyst (Bio-Rad Laboratories) and normalized to that of the signal for $A c t b$ mRNA.

\section{Assay for colony-forming ability of bacteria}

Homogenates of testes were plated at serial dilutions on agarsolidified Luria broth containing X-gal, and the plates were incubated at $37^{\circ} \mathrm{C}$ for $10-16 \mathrm{~h}$. The plates containing 1002000 colonies were subjected to the enumeration of blue colonies, and the number of blue colonies per testis was calculated. The mean \pm s.D. of results obtained with 3-5 testes were presented.

\section{Data processing and statistical analysis}

Data from quantitative analyses are expressed as the mean \pm s.D. $(n \geq 3)$. Statistical analyses were performed using Student's $t$-test, and $P$ values $<0.05$ were considered significant. The data significantly different from controls are marked with asterisks.

\section{Declaration of interest}

There is no conflict of interest.

\section{Funding}

This study was supported by the Grant-in-Aid for Scientific Research from Japan Society for the Promotion of Science (grant number 18791116), an institutional research grant of Kanazawa University, and grants from Takeda Science Foundation and Kurita Water and Environment Foundation.

\section{Acknowledgements}

We thank Kazuhisa Sekimizu and Naofumi Mukaida for the gifts of E. coli and mouse Tnf cDNA respectively.

\section{References}

Bellgrau D, Gold D, Selawry H, Moore J, Franzusoff A \& Duke RC 1995 A role for CD95 ligand in preventing graft rejection. Nature 377 630-632.

Bhushan S, Schuppe H-C, Tchatalbachev S, Fijak M, Weidner W, Chakraborty T \& Meinhardt A 2008a Testicular innate immune defense against bacteria. Molecular and Cellular Endocrinology [in press]. DOI: 10.1016/j.mce.2008.10.017.

Bhushan S, Tchatalbachev S, Klug J, Fijak M, Pineau C, Chakraborty T \& Meinhardt A 2008b Uropathogenic Escherichia coli block MyD88dependent and activate MyD88-independent signaling pathways in rat testicular cells. Journal of Immunology 180 5537-5547.

Carson MJ, Doose JM, Melchior B, Schmid CD \& Ploix CC 2006 CNS immune privilege: hiding in plain sight. Immunological Reviews 213 $48-65$.

Chomczynski P \& Sacchi N 1987 Single-step method of RNA isolation by acid guanidinium thiocyanate-phenol-chloroform extraction. Analytical Biochemistry 162 156-159.

De KS, Chen H-L, Pace JL, Hunt JS, Terranova PF \& Enders GC 1993 Expression of tumor necrosis factor- $\alpha$ in mouse spermatogenic cells. Endocrinology 133 389-396.

Demir A, Türker P, Önol FF, Sirvanci S, Findik A \& Tarcan T 2007 Effect of experimentally induced Escherichia coli epididymo-orchitis and ciprofloxacin treatment on rat spermatogenesis. International Journal of Urology 14 268-272.

Fijak M \& Meinhardt A 2006 The testis in immune privilege. Immunological Reviews 213 66-81.

Fraczek M, Szumala-Kakol A, Jedrzejczak P, Kamieniczna M \& Kurpisz M 2007 Bacteria trigger oxygen radical release and sperm lipid peroxidation in in vivo model of semen inflammation. Fertility and Sterility 88 1076-1085.

Gerdprasert O, O'Bryan MK, Nikolic-Paterson DJ, Sebire K, de Kretser DM \& Hedger MP 2002 Expression of monocyte chemoattractant protein-1 and macrophage colony-stimulating factor in normal and inflamed rat testis. Molecular Human Reproduction 8 518-524.

Girling JE \& Hedger MP 2007 Toll-like receptors in the gonads and reproductive tract: emerging roles in reproductive physiology and pathology. Immunology and Cell Biology 85 481-489.

Gow RM, O'Bryan MK, Canny BJ, Ooi GT \& Hedger MP 2001 Differential effects of dexamethasone treatment on lipopolysaccharide-induced testicular inflammation and reproductive hormone inhibition in adult rats. Journal of Endocrinology 168 193-201.

Grandjean V, Vincent S, Martin L, Rassoulzadegan M \& Cuzin F 1997 Antimicrobial protection of the mouse testis: synthesis of defensins of the cryptdin family. Biology of Reproduction 57 1115-1122.

Griffith TS, Brunner T, Fletcher SM, Green D \& Ferguson TA 1995 Fas ligand-induced apoptosis as a mechanism of immune privilege. Science 270 1189-1192.

Guttman JA, Li Y, Wickham ME, Deng W, Vogl AW \& Finlay BB 2006 Attaching and effacing pathogen-induced tight junction disruption in vivo. Cellular Microbiology 8 634-645.

Hew KW, Heath GL, Jiwa AH \& Welsh MJ 1993 Cadmium in vivo causes disruption of tight junction-associated microfilaments in rat Sertoli cells. Biology of Reproduction 49 840-849.

Hunt JS 2006 Stranger in a strange land. Immunological Reviews 213 36-47.

Ishida Y, Kondo T, Kimura A, Matsushima K \& Mukaida N 2006 Absence of IL-1 receptor antagonist impaired wound healing along with aberrant NF-kappaB activation and a reciprocal suppression of TGF-beta signal pathway. Journal of Immunology 176 5598-5606.

Iwai K, Miyawaki T, Takizawa T, Konno A, Ohta K, Yachie A, Seki H \& Taniguchi N 1994 Differential expression of bcl-2 and susceptibility to anti-Fas-mediated cell death in peripheral blood lymphocytes, monocytes, and neutrophils. Blood 84 1201-1208.

Lennartsson A, Pieters K, Vidovic K \& Gullberg U 2005 A murine antibacterial ortholog to human bactericidal/permeability-increasing protein (BPI) is expressed in testis, epididymis, and bone marrow. Journal of Leukocyte Biology 77 369-377.

Li MWM, Xia W, Mruk DD, Wang CQF, Yan HHN, Siu MKY, Lui W, Lee WM \& Cheng CY 2006 Tumor necrosis factor $\alpha$ reversibly disrupts the blood-testis barrier and impairs Sertoli-germ cell adhesion in the seminiferous epithelium of adult rat testes. Journal of Endocrinology 190 313-329. 
Lui WY \& Cheng CY 2007 Regulation of cell junction dynamics by cytokines in the testis - a molecular and biochemical perspective. Cytokine \& Growth Factor Reviews 18 299-311.

Lui WY \& Lee MW 2006 Regulation of junction dynamics in the testes transcriptional and post-transcriptional regulations of cell junction proteins. Molecular and Cellular Endocrinology 250 25-35.

Lui WY, Mruk D, Lee WM \& Cheng CY 2003 Sertoli cell tight junction dynamics: their regulation during spermatogenesis. Biology of Reproduction 68 1087-1097.

Maeda Y, Shiratsuchi A, Namiki M \& Nakanishi Y 2002 Inhibition of sperm production in mice by annexin $\mathrm{V}$ microinjected into seminiferous tubules: possible etiology of phagocytic clearance of apoptotic spermatogenic cells and male infertility. Cell Death and Differentiation 9 742-749.

Mukasa A, Hiromatsu K, Matsuzaki G, O'Brien R, Born W \& Nomoto K 1995 Bacterial infection of the testis leading to autoaggressive immunity triggers apparently opposed responses of $\alpha \beta$ and $\gamma \delta$ T Cells. Journal of Immunology 155 2047-2056.

Nagaosa K, Shiratsuchi A \& Nakanishi Y 2002 Determination of cell type specificity and estrous cycle dependency of monocyte chemoattractant protein-1 expression in corpora lutea of normally cycling rats in relation to apoptosis and monocyte/macrophage accumulation. Biology of Reproduction 67 1502-1508.

Nagaosa K, Shiratsuchi A \& Nakanishi Y 2003 Concomitant induction of apoptosis and expression of monocyte chemoattractant protein-1 in cultured rat luteal cells by nuclear factor-kappaB and oxidative stress. Development, Growth \& Differentiation 45 351-359.

Nagaosa K, Kishimoto A, Kizu R, Nakagawa A, Shiratsuchi A \& Nakanishi Y 2007 Perturbation of spermatogenesis by androgen antagonists directly injected into seminiferous tubules of live mice. Reproduction 133 21-27.

Nagaosa K, Aikoshi I, Hasegawa Y \& Nakanishi Y 2008 Activator protein 1-mediated expression of monocyte chemoattractant protein 1 in cultured rat luteal cells. Molecular Reproduction and Development75 1077-1084.

Nakagawa A, Shiratsuchi A, Tsuda K \& Nakanishi Y 2005 In vivo analysis of phagocytosis of apoptotic cells by testicular Sertoli cells. Molecular Reproduction and Development 71 166-177.

Nakanishi Y \& Shiratsuchi A 2004 Phagocytic removal of apoptotic spermatogenic cells by Sertoli cells: mechanisms and consequences. Biological \& Pharmaceutical Bulletin 27 13-16.

Niederkorn JY 2007 Immune mechanisms of corneal allograft rejection. Current Eye Research 32 1005-1016.
Palladino MA, Johnson TA, Gupta R, Chapman JL \& Ojha P 2007 Members of the Toll-like receptor family of innate immunity pattern-recognition receptors are abundant in the male rat reproductive tract. Biology of Reproduction 76 958-964.

Riccioli A, Starace D, Galli R, Fuso A, Scarpa S, Palombi F, Cesaris PD, Ziparo E \& Filippini A 2006 Sertoli cells initiate testicular innate immune responses through TLR activation. Journal of Immunology 177 $7122-7130$.

Sang Y, Ortega MT, Blecha F, Prakash O \& Melgarejo T 2005 Molecular cloning and characterization of three beta-defensins from canine testes. Infection and Immunity 73 2611-2620.

Sanocka-Maciejewska D, Ciupińska M \& Kurpisz M 2005 Bacterial infection and semen quality. Journal of Reproductive Immunology 67 51-56.

Siu MKY, Lee WM \& Cheng CY 2003 The interplay of collagen IV, tumor necrosis factor- $\alpha$, gelatinase B (matrix metalloprotease-9), and tissue inhibitor of metalloprotease- 1 in the basal lamina regulates Sertoli celltight junction dynamics in the rat testis. Endocrinology 144 371-387.

Stefanovic L, Brenner DA \& Stefanovic B 2005 Direct hepatotoxic effect of $\mathrm{KC}$ chemokine in the liver without infiltration of neutrophils. Experimental Biology and Medicine 230 573-586.

Wang CQF \& Cheng CY 2007 A seamless trespass: germ cell migration across the seminiferous epithelium during spermatogenesis. Journal of Cell Biology 178 549-556.

Wiebe JP, Kowalik A, Gallardi RL, Egeler O \& Clubb BH 2000 Glycerol disrupts tight junction-associated actin microfilaments, occludin, and microtubules in Sertoli cells. Journal of Andrology 21 625-635.

Wu H, Wang H, Xiong W, Chen S, Tang H \& Han D 2008 Expression patterns and functions of Toll-like receptors in mouse Sertoli cells. Endocrinology 149 4402-4412.

Xia W, Mruk DD, Lee WM \& Cheng CY 2005 Cytokines and junction restructuring during spermatogenesis - a lesson to learn from the testis. Cytokine \& Growth Factor Reviews 16 469-493.

Received 4 November 2008

First decision 9 December 2008

Revised manuscript received 9 February 2009

Accepted 18 February 2009 